\title{
Outcome of Undergraduate Medical Education using Medical Simulation according to Students' Feedback
}

\section{خرجات التعليم الطبي الجامعي باستخدام المحاكاة الطبية وفقًا لملاحظات الطلاب}

$$
\text { سلمان رياض، أحمد عبد الكريم جرادات، رويل جوتيريز، تيسير سعيد جرادة }
$$

\begin{abstract}
Objectives: This study aimed to determine students' overall satisfaction with clinical simulation sessions and compare the satisfaction levels of obstetrics/gynaecology (OBGYN) students (group one) and internal medicine students (group two). Methods: This study was conducted from January to June 2019 at the Arabian Gulf University, Manama, Bahrain. Students from year five were included and offered sessions that used simulations to support clinical skill development. Data were collected using a five-point Likert scale (i.e. strongly agree, agree, neutral, disagree, strongly disagree) via feedback forms. Results: A total of 150 students were included in this study (response rate: 99.07\%). In groups of seven, the students attended five cycles of simulations with two sessions per cycle in each specialty over six months. The mean percentage of responses of "strongly agree" and "agree" was 97.8 $\pm 2.3 \%$ in group one and $95.7 \pm 2.7 \%$ in group two. The satisfaction scores of group one were higher than those from group two for all statements. Significant differences were found between groups one and two in their responses to the statement of whether the simulation session was relevant to clinical practice $(100 \%$ versus $92.9 \% ; P<0.001)$ and whether the debriefing session was useful $(98.1 \%$ versus $94.8 \% ; P=0.015)$. Conclusion: Students indicated high satisfaction after attending the simulation sessions; however, OBGYN students were more satisfied compared to those studying internal medicine.
\end{abstract}

Keywords: Simulation Training; Patient Simulation; High Fidelity Simulation Training; Undergraduate Medical Education; Bahrain.

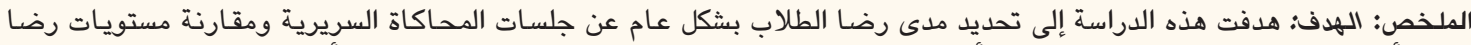

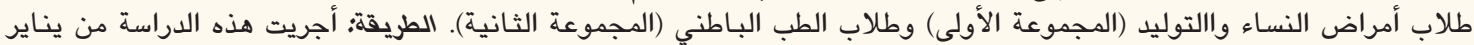

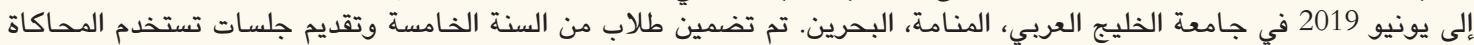

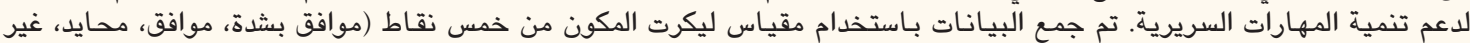

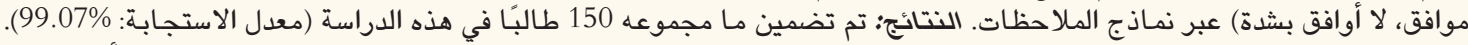

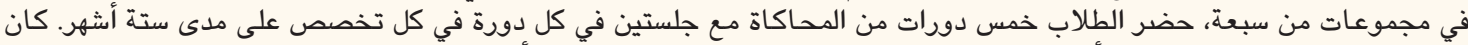

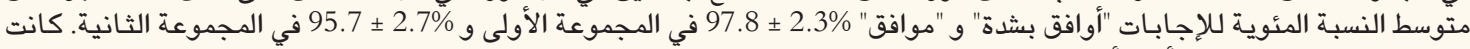

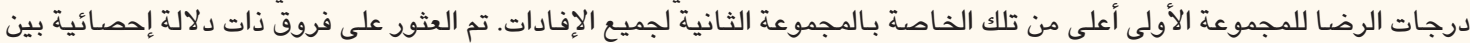

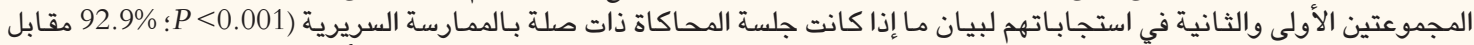

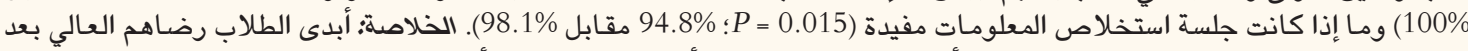

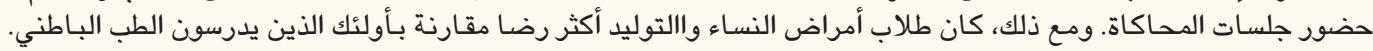

$$
\text { الكلمات المفتاحية؛ تدريب المحاكاة؛ محاكاة المريض؛ تدريب محاكاة عالي الدقة؛ التعليم الطبي في المرحلة الجامعية؛ البحرين. }
$$

\section{AdVANCES IN KNOWLEDGE}

Students from obstetrics/gynaecology (OBGYN) and internal medicine specialities found simulation-based learning helpful for improving their clinical skills.

OBGYN students were more satisfied with the clinical simulation sessions than internal medicine students because they were able to practice cases they would not normally be able to work with in ward-based teaching due to reasons such as patient privacy and discomfort.

\section{Application to Patient Care}

Simulation can be especially useful for improving clinical skills in specialties that require hands-on practice, but fewer opportunities are given to practice the procedures due to the critical nature of cases or patient concerns.

Undergraduates can be trained in both technical and non-technical skills using simulation-based education, as it fosters higher retention of knowledge and improves students' future practice. 
C LINICAL SKILLS TRAINING IS AN IMPORTANT part of medical education because it plays a key role in training medical students to become qualified clinicians. ${ }^{1}$ Developing clinical skills requires a systematic approach for solving problems and providing skills appropriate for working with a team of clinicians; however, developing these skills is a major challenge for undergraduate medical students. ${ }^{2}$

To address this challenge, simulation has been incorporated in undergraduate medical curricula as it provides real experience to students without harming patients. $^{3}$ Research has suggested that simulationbased learning better improves clinical skills and undergraduate comprehension compared to casebased discussions. ${ }^{4}$ Issues such as patient safety, the busy schedules of consultants/specialist doctors, limited availability of real patients for training purposes and other related factors have led to the introduction of simulation laboratories and clinical skills practice centres to train medical students. ${ }^{5}$ Medical simulation is an increasingly familiar tool in many countries and is becoming progressively dominant in medical and surgical training. ${ }^{6-9}$ Research and advancements are needed to develop methods which can be used to address the issue of training undergraduates for clinical skills in the best possible ways. A literature review was conducted and studies from 2006-2016 showed that concern about patient safety is not new, as it is recognised in many countries with global awareness fostered by World Health Organisation's World Alliance for Patient Safety which started in 2004. ${ }^{10}$ However, there is very little literature comparing the usefulness of simulation-based teaching between certain specialities.

The Medical Skills and Simulation Centre (MSSC) at Arabian Gulf University (AGU), Manama, Bahrain, was launched in January 2018. The aim of the centre is to incorporate medical simulation in the undergraduate medical curriculum, providing a platform for undergraduate medical students to improve their clinical, communication and nontechnical skills (i.e. human factors) so that their practice can contribute to an improved healthcare system. The centre consists of clinical simulation rooms with high-fidelity manikins and part-task trainers which are used along with standardised patients and debriefing rooms. Part-task trainers are used to improve skills and high-fidelity simulators are used to improve competencies with full clinical immersion. Both provide the opportunity to practice different clinical cases and scenarios. Currently, medical simulation is introduced to students in the clinical year (year five) for OBGYN and internal medicine specialties.
This study aimed to determine the overall satisfaction levels of students at the end of every clinical simulation session and compare these levels between OBGYN and internal medicine students. In addition, this study aimed to evaluate the usefulness of high-fidelity manikins and part-task trainers in simulation-based teaching for undergraduate medical students in these two specialties.

\section{Methods}

This prospective observational cross-sectional study was conducted from January to June 2019 at AGU, Manama, Bahrain. Students in the clinical year (year five) of the Doctor of Medicine (MD) programme were offered five simulation cycles and each cycle had two sessions for a total of 10 sessions in each specialty; these cycles were offered during their rotation in the OBGYN (group one) and internal medicine (group two) specialties. The scenarios for simulated sessions were prepared by faculty members, all of whom were experienced doctors with clinical teaching experience. The scenarios were developed in accordance with the curricula of both specialties and were validated by the simulation expert of the MSSC. Training on the basics of medical simulation, facilitating sessions and using high/low-fidelity manikins was provided to the faculty members by relevant experts before teaching started in the centre.

Clinical simulation instructors facilitated the sessions, starting with pre-briefing followed by clinical immersion, hands-on clinical practice and debriefing. The instructors were aware that student feedback would be collected at the end of the sessions. The students were divided into groups of seven for each simulation activity; each simulation activity was two hours long. This rotation was repeated on different days to accommodate all the students/groups.

In the simulation sessions, two of the students were assigned the role of active participants while other students were observers. Jobs were distributed among the observers to closely monitor the active participants for aspects of clinical immersion, such as approaching the patient, taking patient history, conducting clinical examinations, carrying out investigations, undertaking patient management, assessing patient concerns/comfort, communicating with the patient and colleagues and corresponding with a consultant/senior doctor via the phone to present the case for further advice. To maximise the efficacy of the sessions, the observers were also asked to note the strengths and deficiencies of the active participants' performances for discussion during the debriefing. 
iStan (CAE Healthcare, Inc., Florida, United States), a high-fidelity manikin, was used for the internal medicine sessions. The part-task trainers for this specialty included: (1) a lumbar puncture trainer, (2) OpthoSim (OtoSim, Inc., Toronto, Canada) for practicing fundoscopy including retinal pathologies; (3) an abdominal examination trainer with different pathology options including organomegalies, aortic/ renal artery bruit and ascites and (4) other training aids. For OBGYN sessions, the high-fidelity manikin, Lucina (CAE Healthcare Inc., Florida, United States), was used along with part-task trainers that allowed for practicing pertinent skills, such as identifying cervical abnormalities and taking specimens for a cervical smear.

At the end of each two-session cycle, student feedback was collected through a five-point Likert scale and included eight statements regarding the session, with responses ranging from "strongly agree" to "strongly disagree" [Table 1]. The data were stored and analysed using Statistical Package for the Social Sciences (SPSS), Version 14.0 (SPSS, Inc., Chicago, Illinois, USA). Descriptive statistical measurements of percentage and mean were used to analyse the data. The students' overall satisfaction with the simulation sessions was estimated by calculating the percentage of the "strongly agree" and "agree" fields for each item. The "strongly agree" and "agree" responses were assigned a numerical value of one while the remainder of the responses were assigned a numerical value of zero. An independent samples t-test was conducted to compare significant differences in the satisfaction levels between the two groups. A $P$ value $<0.05$ was

Table 1: Statements used to determine students' satisfaction with clinical simulation sessions at the Arabian Gulf University, Manama, Bahrain

\begin{tabular}{|c|c|}
\hline $\begin{array}{l}\text { Statement } \\
\text { number }\end{array}$ & Statement* \\
\hline 1 & The pre-briefing was easy to understand \\
\hline 2 & $\begin{array}{l}\text { The learning outcome of the session were } \\
\text { easy to understand }\end{array}$ \\
\hline 3 & $\begin{array}{l}\text { The session was relevant to your clinical } \\
\text { practice }\end{array}$ \\
\hline 4 & $\begin{array}{c}\text { You were given the opportunity to discuss } \\
\text { this session in the debriefing }\end{array}$ \\
\hline 5 & The debriefing session was useful \\
\hline 6 & $\begin{array}{l}\text { Facilitator/staff in this session were } \\
\text { competent }\end{array}$ \\
\hline 7 & The session was useful to you \\
\hline 8 & $\begin{array}{c}\text { Overall, today's session was good and well } \\
\text { organised }\end{array}$ \\
\hline
\end{tabular}

considered statistically significant. Data collection was halted after six months of offering the sessions, once 75 students had completed their OBGYN cycle and the other 75 had completed the internal medicine cycle.

This study was approved by the Ethics and Research Committee of AGU (E007-PI-04/18). As personal views were required, respect for participants' rights, anonymity and dignity was given constant consideration. The forms did not collect student names, gender or identification numbers and were kept anonymous. An information sheet stating the purpose and aim of the study was attached to each form.

\section{Results}

A total of 150 students participated in this study (response rate: 99.07\%). As all students present for the sessions were offered feedback forms at the end of each cycle and there were a total of five different cycles, the potential total feedback was 375 forms. In total, 373 and 370 forms were received from groups one and two, respectively. All forms with incomplete responses were excluded. Finally, a total of 371 and 367 forms from groups one and two were used for analyses.

The average percentage demonstrating the satisfaction of students was $97.8 \pm 2.3 \%$ in group one and $95.7 \pm 2.7 \%$ in group two [Table 2]. Of the students, $93.3 \%$ in group one and $92.4 \%$ in group two responded that the prebriefing session was easy to understand (statement one; $P=0.639$ ). Moreover, $96.2 \%$ and $94.3 \%$ of students from groups one and two, respectively, indicated satisfaction that the learning outcomes of the simulation sessions were easy to understand (statement two; $P=0.213$ ). All the students from group one agreed that the simulation sessions were relevant to their clinical practice (statement three); however, only $92.9 \%$ of the students in group two found them to be relevant; this finding showed a statistically significant difference between the groups $(P<0.001)$. Concerning the opportunity to discuss the sessions during debriefing (statement four), $97 \%$ of the students from group one and $95.1 \%$ of the students from group two demonstrated satisfaction $(P=$ 0.175). With regard to the usefulness of the debriefing sessions after the simulation experience (statement five), $98.1 \%$ and $94.8 \%$ of the students from groups one and two, respectively, agreed that they were useful; this finding indicated a significant difference between the two groups $(P=0.015)$. The competency of the facilitators and staff (statement six) received high levels of satisfaction; 100\% from group one and 99.5\% from group two $(P=0.154)$. Of the students, $98.4 \%$ 
Table 2: Mean scores of participants in the specialties of obstetrics/gynaecology and internal medicine who strongly agreed or agreed with the questionnaire's statements

\begin{tabular}{|c|c|c|}
\hline $\begin{array}{l}\text { Statement } \\
\text { number }\end{array}$ & Speciality & $\begin{array}{c}\text { Mean score } \\
\text { (\%) }\end{array}$ \\
\hline \multirow[t]{2}{*}{1} & OBGYN & 0.932 (93.3) \\
\hline & Internal medicine & $0.923(92.4)$ \\
\hline \multirow[t]{2}{*}{2} & OBGYN & $0.962(96.2)$ \\
\hline & Internal medicine & $0.942(94.3)$ \\
\hline \multirow[t]{2}{*}{3} & OBGYN & $1(100)$ \\
\hline & Internal medicine & 0.929 (92.9) \\
\hline \multirow[t]{2}{*}{4} & OBGYN & $0.97(97)$ \\
\hline & Internal medicine & $0.95(95.1)$ \\
\hline \multirow[t]{2}{*}{5} & OBGYN & $0.981(98.1)$ \\
\hline & Internal medicine & $0.948(94.8)$ \\
\hline \multirow[t]{2}{*}{6} & OBGYN & $1(100)$ \\
\hline & Internal medicine & 0.994 (99.5) \\
\hline \multirow[t]{2}{*}{7} & OBGYN & $0.983(98.4)$ \\
\hline & Internal medicine & $0.97(97)$ \\
\hline \multirow[t]{2}{*}{8} & OBGYN & 0.994 (99.5) \\
\hline & Internal medicine & 0.991 (99.2) \\
\hline \multirow{2}{*}{$\begin{array}{l}\text { Overall mean score } \\
\text { (mean percentage } \\
\pm \text { SD) }\end{array}$} & OBGYN & $0.98(97.8 \pm 2.3)$ \\
\hline & Internal medicine & $0.96(95.7 \pm 2.7)$ \\
\hline
\end{tabular}

from group one and $97 \%$ from group two found the sessions useful (statement seven; $P=0.211$ ). Finally, the percentage of overall satisfaction (statement eight) in both groups was similar; $99.5 \%$ and $99.2 \%$ in groups one and two, respectively $(P=0.645)$ [Table 3].

\section{Discussion}

The fundamental aim of healthcare education is to produce doctors who not only possess a good level of knowledge but are also capable of practically applying that knowledge. ${ }^{11}$ Applying such knowledge during medical practice means possessing clinical and patient management skills; however, developing these skills is a major challenge for future doctors. ${ }^{5}$ Many international bodies and institutions have universally agreed that, although clinical skills are key to medical practice, most undergraduate students who complete their programmes have theoretical knowledge but lack competence in clinical skills due to inadequate resources and opportunities. ${ }^{5}$ This persistent issue suggests the need to revise medical curricula and include simulation-based teaching, which provides an opportunity for students to apply their knowledge
Table 3: Summary of results by statement response according to specialty

\begin{tabular}{|c|c|c|c|c|}
\hline \multirow{2}{*}{$\begin{array}{l}\text { Statement } \\
\text { number }\end{array}$} & \multirow[t]{2}{*}{ Specialty } & \multicolumn{2}{|c|}{$\mathbf{n}(\%)^{*}$} & \multirow{2}{*}{$\begin{array}{c}P \\
\text { value }\end{array}$} \\
\hline & & $\begin{array}{c}\text { Not } \\
\text { satisfied }\end{array}$ & Satisfied & \\
\hline \multirow[t]{2}{*}{1} & OBGYN & $25(6.7)$ & $346(93.3)$ & 0.639 \\
\hline & $\begin{array}{l}\text { Internal } \\
\text { medicine }\end{array}$ & $28(7.6)$ & 339 (92.4) & \\
\hline \multirow[t]{2}{*}{2} & OBGYN & $14(3.8)$ & $357(96.2)$ & 0.213 \\
\hline & $\begin{array}{l}\text { Internal } \\
\text { medicine }\end{array}$ & $21(5.7)$ & $346(94.3)$ & \\
\hline \multirow[t]{2}{*}{3} & OBGYN & $0(0)$ & $371(100)$ & $\begin{array}{c}< \\
0.001\end{array}$ \\
\hline & $\begin{array}{l}\text { Internal } \\
\text { medicine }\end{array}$ & $26(7.1)$ & 341 (92.9) & \\
\hline \multirow[t]{2}{*}{4} & OBGYN & $11(3.0)$ & $360(97.0)$ & 0.175 \\
\hline & $\begin{array}{l}\text { Internal } \\
\text { medicine }\end{array}$ & $18(4.9)$ & $349(95.1)$ & \\
\hline \multirow[t]{2}{*}{5} & OBGYN & $7(1.9)$ & 364 (98.1) & 0.015 \\
\hline & $\begin{array}{l}\text { Internal } \\
\text { medicine }\end{array}$ & $19(5.2)$ & $348(94.8)$ & \\
\hline \multirow[t]{2}{*}{6} & OBGYN & $0(0)$ & $371(100)$ & 0.154 \\
\hline & $\begin{array}{l}\text { Internal } \\
\text { medicine }\end{array}$ & $2(0.5)$ & 365 (99.5) & \\
\hline \multirow[t]{2}{*}{7} & OBGYN & $6(1.6)$ & 365 (98.4) & 0.211 \\
\hline & $\begin{array}{l}\text { Internal } \\
\text { medicine }\end{array}$ & $11(3.0)$ & $356(97.0)$ & \\
\hline \multirow[t]{2}{*}{8} & OBGYN & $2(0.5)$ & 369 (99.5) & 0.645 \\
\hline & $\begin{array}{l}\text { Internal } \\
\text { medicine }\end{array}$ & $3(0.8)$ & $364(99.2)$ & \\
\hline
\end{tabular}

"Internal medicine total response $=367 ;$ OBGYN total response $=371$ $O B G Y N=$ obstetrics and gynaecology.

before beginning clinical practice. ${ }^{11}$

The findings of this study suggest that students involved in simulation-based training were highly satisfied overall with the sessions, finding them beneficial for practicing what they had previously theoretically learnt. These results are in accordance with a study conducted by Agha et al., in which undergraduate medical students reported that simulation-based learning is useful for improving knowledge retention and enhancing decision-making skills. ${ }^{12}$ Moreover, the results agreed with the findings of a study in which medical students found that clinical simulation sessions were a unique opportunity to learn by practicing and the students received feedback on their practice. ${ }^{2}$ Medical education using simulation, therefore, might be used to train doctors who possess the confidence and skills to handle problems in reallife cases at their workplace. ${ }^{11}$ Researchers have demonstrated that competence is directly related 
to confidence, and simulation-based education can be used to build confidence because it provides opportunities to practice difficult cases without fear of errors. ${ }^{11,13}$

High-fidelity simulators were used in the MSSC to train students from two specialties; the students' satisfaction demonstrated that, when the high-fidelity simulation was facilitated in the form of small groups, it was preferred to any other laboratory experience. ${ }^{14}$ The noticeable difference in mean values showed that students in group one were more satisfied than students in group two after attending the simulation sessions. Also, results with a low standard deviation in both groups showed that there was little variation among the students' opinions; most of the students attending the simulation sessions were satisfied. However, two major statements about relevance to clinical practice and usefulness of the debriefing sessions received a significantly different response from both groups. The students in group one felt that the sessions were more relevant to their clinical practice than the students in group two. This finding suggests that group one learners found simulation-based sessions helpful in acquiring specific medical skills required in the OBGYN specialty. Similarly, group one scored higher than group two on the statement concerning the debriefing sessions' usefulness. Although both groups' sessions were conducted similarly, using related techniques, resources, high-fidelity manikins, part-task trainers and standardised patients, group one indicated a higher percentage of satisfaction than group two students for every statement.

Students usually do not receive opportunities to practice certain clinical cases in the OBGYN specialty due to the risk of complications and the critical nature of some cases. Also contributing to this shortage of opportunities is the desire to prevent patient discomfort, maintain patient privacy and remain culturally sensitive. Furthermore, opportunities are not often available in real-time learning in this specialty due to patient safety issues, which is an important consideration. In AGU, teaching in this specialty was previously done using traditional medical education methods in which theoretical knowledge was given in didactic sessions and students later observed some cases or practiced on patients. ${ }^{15}$ Although teaching in internal medicine was done in the same way, there are generally fewer privacy and cultural issues restraining students from practicing in ward-based teaching. Ultimately, medical simulation is similar to real-time cases, but it provides increased accuracy and no fear of errors. ${ }^{16}$ The students in group one, therefore, might have found the sessions to be closer to the reality of clinical practice, in addition to providing training in an area otherwise not available to them. The results demonstrated that the students found combining the simulation with traditional medical education methods in the OBGYN specialty useful for reducing the shortcomings of medical errors due to lack of practice. $^{17}$

Although this study did not aim to compare simulation-based teaching with clinical placements, previous studies have recommended that simulated sessions should only be an addition to medical curricula and should not replace clinical placements. ${ }^{18}$ The present study found high satisfaction levels of students in simulation sessions, suggesting that more sessions should be planned for various specialties such as anaesthesia, intensive care medicine, radiology and emergency medicine and for paramedics, nurses and respiratory therapists. ${ }^{19-21}$ Expanding exposure to simulations would provide learning experiences that can improve healthcare practices broadly. Simulationbased training might also play a vital role in increasing the competence of undergraduates and junior doctors, especially in acute clinical cases which are difficult to practice because of their rarity and life-threatening nature. $^{22}$

Although the outcomes showed that students were satisfied with the sessions overall, this study faced some limitations. Open-ended comments or suggestions were not gathered on the feedback forms; adding them might yield qualitative information about how students understood the scenarios or might present more informed differences between the groups. Although information on participants' genders were not collected, having that data would have been helpful in analysing the results, particularly for the OBGYN speciality where male students receive fewer chances to practice with real cases due to patient preferences. Future studies, therefore, should enquire about the participants' gender for more clarity in the analyses. This study was conducted with a small sample size and only two specialties; hence, the findings cannot be generalised. Another study with an increased sample size could be planned after one or two years so that there is sufficient time for the courses offered at the centre to be evaluated and improved if necessary. Moreover, longitudinal studies could also be conducted to detect changes in responses over time. The findings of the study will be utilised to plan advancements in the centre and future simulation training. Although simulation-based learning in this study was specific to two specialties only, the study's findings can be modified to design courses applicable to more specialties. 


\section{Conclusion}

This study found a high student satisfaction of simulation sessions, indicating that they found simulation-based learning helpful for improving their skills. OBGYN students were more satisfied with the sessions compared to internal medicine students. These results were probably due to the fact that simulations are useful for improving clinical skills that require hands-on practice but are difficult to perform. Relatively few opportunities to perform these skills are available due to the critical nature of some cases, patient privacy concerns and a desire to avoid patient discomfort in specialties such as gynaecology. Concrete, real-life encounters produce higher knowledge and skill retention and help improve the future practices of students. Similarly, undergraduates can learn both technical and non-technical skills using simulation-based training including managing rare cases, developing appropriate knowledge, attitudes, and communication skills and directing teams and resources. This study will help university curriculum planners and stakeholders add further simulation sessions for different specialities and improve educational experiences.

\section{CONFLICT OF INTEREST}

The authors declare no conflicts of interest.

\section{FUNDING}

No funding was received for this study.

\section{ACKNOWLEDGEMENTS}

We acknowledge the contribution of Misbah Tabassum in the preparation, editing, proofreading and review of the manuscript.

\section{References}

1. Wang Z, Liu Q, Wang H. Medical simulation-based education improves medicos' clinical skills. J Biomed Res 2013; 27:81-4. https://doi.org/10.7555/JBR.27.20120131.

2. Weller JM. Simulation in undergraduate medical education: Bridging the gap between theory and practice. Med Educ 2004; 38:32-8. https://doi.org/10.1111/j.1365-2923.2004.01739.x.

3. Vattanavanit V, Kawla-Ied J, Bhurayanontachai R. Highfidelity medical simulation training improves medical students' knowledge and confidence levels in septic shock resuscitation. Open Access Emerg Med 2016; 9:1-7. https://doi.org/10.2147/ OAEM.S122525.

4. Littlewood KE, Shilling AM, Stemland CJ, Wright EB, Kirk MA High-fidelity simulation is superior to case-based discussion in teaching the management of shock. Med Teach 2013; 35:e1003-10. https://doi.org/10.3109/0142159X.2012.733043.

5. Al-Elq AH. Simulation-based medical teaching and learning. J Family Community Med 2010; 17:35-40. https://doi. org/10.4103/1319-1683.68787.
6. Okuda Y, Bond W, Bonfante G, McLaughlin S, Spillane L, Wang E, et al. National growth in simulation training within emergency medicine residency programs, 2003-2008. Acad Emerg Med 2008; 15:1113-16. https://doi.org/10.1111/j.15532712.2008.00195.x

7. LeBlanc V, Bould MD, McNaughton N, Brydges R, Piquette D, Sharma B. 18 Simulation in postgraduate medical education co-leads. From: https://pdfs.semanticscholar.org/2f18/0f6 0927d2265145b4e280481d61daf569d16.pdf Accessed: Feb 2020

8. Issenberg SB, McGaghie WC, Petrusa ER, Lee Gordon D, Scalese RJ. Features and uses of high-fidelity medical simulations that lead to effective learning: A BEME systematic review. Med Teach 2005;27:10-28. https://doi.org/10.1080/01421590500046924.

9. McGaghie WC, Issenberg SB, Petrusa ER, Scalese RJ. A critical review of simulation based medical education research: 20032009. Med Educ 2010; 44:50-63. https://doi.org/10.1111/ j.1365-2923.2009.03547.x.

10. Emanuel L, Berwick D, Conway J, et al. What exactly is patient safety? In: Henrisken K, Battles JB, Keyes MA, et al., editors. Advances in Patient Safety: New Directions and Alternative Approaches (Vol. 1: Assessment). Rockvile (MD): Agency for Healthcare Research and Quality; 2008. Available from: https:// www.ncbi.nlm.nih.gov/books/NBK43629.

11. Abas T, Juma FZ. Benefits of simulation training in medical education. Adv Med Educ Pract 2016; 7:399-400. https://doi. org/10.2147/AMEP.S110386.

12. Agha S, Alhamrani AY, Khan MA. Satisfaction of medical students with simulation-based learning. Saudi Med J 2015; 36:731-6. https://doi.org/10.15537/smj.2015.6.11501.

13. Hecimovich M, Volet S. Development of professional confidence in health education: Research evidence of the impact of guided practice into the profession. Health Educ 2011; 111:177-97. https://doi.org/10.1108/09654281111123475

14. Euliano TY. Small group teaching: Clinical correlation with a human patient simulator. Adv Physiol Educ 2001; 25:36-43. https://doi.org/10.1152/advances.2001.25.1.36

15. Zhang MY, Cheng X, Xu AD, Luo LP, Yang X. Clinical simulation training improves the clinical performance of Chinese medical students. Med Educ Online 2015; 20:28796. https://doi.org/10.3402/meo.v20.28796.

16. Jang HW, Kim KJ. Use of online clinical videos for clinical skills training for medical students: Benefits and challenges. BMC Med Educ 2014; 14:56. https://doi.org/10.1186/1472-6920-14-56.

17. Back DA, Haberstroh N, Antolic A, Sostmann K, Schmidmaier G, Hoff E. Blended learning approach improves teaching in a problem-based learning environment in orthopedics - A pilot study. BMC Med Educ 2014; 14:17. https://doi.org/10.1186/14 72-6920-14-17.

18. Levett-Jones T, McCoy M, Lapkin S, Noble D, Hoffman K, Dempsey J, et al. The development and psychometric testing of the satisfaction with simulation experience scale. Nurse Educ Today 2011; 31:705-10. https://doi.org/10.1016/j.nedt.2011.0 1.004 .

19. Flanagan B, Nestel D, Joseph M. Making patient safety the focus: Crisis resource management in the undergraduate curriculum. MedEduc2004;38:56-66.https://doi.org/10.1111/j.1365-2923.2 004.01701.x.

20. Cherry RA, Ali J. Current concepts in simulation-based trauma education. J Trauma 2008; 65:1186-93. https://doi.org/10.1097/ TA.0b013e318170a75e.

21. Jeffries PR. A framework for designing, implementing, and evaluating simulation used as teaching strategies in nursing. Nurs Educ Perspect 2005; 26:96-103.

22. Ayres-De-Campos D. Simulation-based training in obstetrics and gynaecology. From: www.fvvo.be/assets/247/07-Ayres-deCampos.pdf Accessed: Feb 2020. 